\title{
$\mathrm{Ti}-44.5 \mathrm{Ni}-5 \mathrm{Cu}$ 및 $\mathrm{Ti}-45.2 \mathrm{Ni}-5 \mathrm{Cu}(\mathrm{at} \%)$ 합금의 형상기억특성에 미치는 어닐링온도의 영향 \\ 김재일 $1, *$. 황광선 ${ }^{2}$ \\ 1동아대학교 신소재공학과 \\ 2동부인천스틸(주) 마케팅실
}

\section{Effect of Annealing Temperature on the Shape Memory Properties of Ti-44.5Ni-5Cu and Ti-45.2Ni-5Cu(at\%) Alloys}

\author{
Jae Il Kim ${ }^{1, *}$ and Kwang Sun Hwang ${ }^{2}$ \\ ${ }^{I}$ Department of materials \& science Engineering, Dong-A University, Busan 49315, Republic of Korea \\ ${ }^{2}$ Corporate office of marketing, Dongbu Incheon Steel Co., Ltd., Seoul 04637, Republic of Korea
}

\begin{abstract}
The effect of annealing temperature on shape memory properties in the Ti-44.5Ni-5Cu and Ti$45.2 \mathrm{Ni}-5 \mathrm{Cu}$ (at\%) alloys was investigated by differential scanning calorimeter (DSC) and tensile testing. The martensitic transformation temperature of Ti- $44.5 \mathrm{Ni}-5 \mathrm{Cu}(\mathrm{at} \%)$ increased from $308 \mathrm{~K}$ to $324 \mathrm{~K}$ with increasing annealing temperature and did not change with further increasing annealing temperature. This is because dislocations decreased with increasing annealing temperature due to recovery and recrystallization. However, the martensitic transformation temperature of Ti- $45.2 \mathrm{Ni}-5 \mathrm{Cu}(\mathrm{at} \%)$ increased from $286 \mathrm{~K}$ to $317 \mathrm{~K}$ with increasing annealing temperature until reaching a maximum, and then decreased with further increasing annealing temperature. This is understood to be due to the decrease of $\mathrm{Ni}$ content in the matrix by the formation of $\mathrm{Ti}(\mathrm{Cu}, \mathrm{Ni})_{2}$ at the lower annealing temperature, and the increase in $\mathrm{Ni}$ content in the matrix by the re-solution of $\mathrm{Ti}(\mathrm{Cu}, \mathrm{Ni})_{2}$ at the higher annealing temperature. The critical stress for slip of Ti-45.2Ni$5 \mathrm{Cu}(\mathrm{at} \%)$ was higher than that of $\mathrm{Ti}-44.5 \mathrm{Ni}-5 \mathrm{Cu}(\mathrm{at} \%)$ at the lower annealing temperature. This is because of precipitation hardening of the $\mathrm{Ti}(\mathrm{Cu}, \mathrm{Ni})_{2}$.
\end{abstract}

(Received May 27, 2019; Accepted July 3, 2019)

Keywords: Ti-Ni-Cu, shape memory alloy, martensite, annealing, transformation temperature

\section{1. 서 론}

Ti-Ni합금은 우수한 형상기억특성뿐만 아니라 내식성, 생 체적합성, 가공성 등이 뛰어나 공업 분야 및 생체분야에서 폭넓게 응용되어지고 있다. 일반적으로 Ti-Ni 합금의 형상 기억 특성에 미치는 인자로써는 냉간가공 후 중간온도에서 의 어닐링처리[1-4], 용체화 처리 후 시효처리[1,2,5-7], 제 3 원소 $(\mathrm{Fe}, \mathrm{Cu}, \mathrm{Al})$ 첨가 [8-10]등을 들 수 있다. Ti-Ni 형 상기억합금은 $\mathrm{CsCl}$ 구조의 $\mathrm{B} 2$ 상, monoclinic 구조의 $\mathrm{B} 19^{\prime}($ Martensite)상과 rhombohedral 구조의 R상 $(\mathrm{R})$ 이 나타

- 김재일: 교수, 황광선: 연구원

*Corresponding Author: Jae Il Kim

[Tel: +82-51-200-7749, E-mail: kimchi@dau.ac.kr]

Copyright (c) The Korean Institute of Metals and Materials
난다고 알려져 있다. 이 상들 사이에서는 $\mathrm{B} 2 \leftrightarrow \mathrm{R}, \mathrm{B} 2 \leftrightarrow \mathrm{M}$, $\mathrm{R} \leftrightarrow \mathrm{M}$ 변태가 일어난다. 이러한 변태는 전위, 석출물 및 제 3원소 첨가 등에 의해 결정되어진다 [11]. 이 세 가지 변태 중 $\mathrm{B} 2 \leftrightarrow \mathrm{B} 19^{\prime}, \mathrm{R} \leftrightarrow \mathrm{B} 19^{\prime}$ 는 큰 격자 뒤틀림과 온도 히스테리시스가 특징이다. 큰 격자 뒤틀림은 반복 변태에 의해 미세조직의 구조적인 결함이 유발되어 열기계적 안정 성이 낮아진다. 그와 대조적으로 $\mathrm{B} 2 \leftrightarrow \mathrm{R}$ 상 변태는 적은 격 자 뒤틀림과 낮은 온도 히스테리시스를 가진다. 작은 격자 뒤틀림에 의해, 반복 변태에도 미세조직의 구조적인 결함 이 적으며, 낮은 히스테리시스에 의해 높은 가역성과 높은 응답율을 보이는 장점이 있다. 이러한 특성에 의해, $\mathrm{R} \leftrightarrow \mathrm{B} 2$ 변태가 가지는 형상기억특성을 이용하여 센서 및 액추에이 터의 후보 재료에 많이 각광 받고 있다. 그러나, $\mathrm{R} \leftrightarrow \mathrm{B} 2$ 변태 시 발생하는 변태변형률은 $1 \%$ 이내로, 여러 액추에 
이터에의 응용이 제한되어진다.

$\mathrm{Ti}-\mathrm{Ni}$ 2원계 합금의 경우 열기계적처리 후 시료의 슬립 임계응력은 크게 상승하지만 마르텐사이트 변태 개시온도 $\left(M_{s}\right)$ 가 크게 저하되고 변태온도 히스테리시스가 증가하여 높은 응답성을 요구하는 액추에이터에 응용은 힘들다고 알 려져 있다 $[12,13]$. 이러한 히스테리시스를 낮추기 위해서 는 $\mathrm{Ti}-\mathrm{Ni}$ 2원계 합금에 $\mathrm{Cu}$ 첨가가 효과적이라고 알려져 있다. 또한 열기계적 처리 후에도 변태온도의 감소폭이 Ti$\mathrm{Ni}$ 2원계 합금보다 작아 액추에이터의 응용에 유리하다. $\mathrm{Cu}$ 원자는 $\mathrm{Ni}$ 원자를 치환하는데 $\mathrm{Cu}$ 의 함량이 $7.5 \%$ 이상일 때 $\mathrm{B} 2 \rightarrow \mathrm{B} 19^{\prime}$ 1단계 변태가 아닌 B2 $\rightarrow \mathrm{B} 19$ (orthorombic) $\rightarrow$ B19' 2단계 마르텐사이트 변태가 나타나며 취성이 강해져 서 가공 및 응용이 힘들어진다 [14-18]. 과거의 연구 대부 분은 등조성내 $50 \mathrm{at} \% \mathrm{Ti}-(50-\mathrm{X}) \mathrm{at} \% \mathrm{Ni}-\mathrm{XCu}$ 합금의 기계적 특성의 조사되어졌으나, $(\mathrm{Ni}, \mathrm{Cu})-\mathrm{Rich} \mathrm{Ti}-\mathrm{Ni}-\mathrm{Cu}$ 합금의 형 상기억합금에 대한 연구는 거의 보고되지 않고 있다. $(\mathrm{Ni}, \mathrm{Cu})-\mathrm{Rich} \mathrm{Ti}-\mathrm{Ni}-\mathrm{Cu}$ 합금은 Ni-rich 석출물에 의한 석 출 경화 효과가 예상이 되며 $\mathrm{Ti}-\mathrm{Ni}-\mathrm{Cu}$ 합금의 특성인 변태 온도 히스테리시스를 감소시키는 특성이 같이 나타날 것 이라고 사료된다. 본 연구는 석출 경화 효과가 나타나지 않는 Ti-rich 조성의 $\mathrm{Ti}-44.5 \mathrm{Ni}-5 \mathrm{Cu}(\mathrm{at} \%)$ 합금과 석출경화 효과가 예상되어지는 Ti-45.2Ni-5Cu(at\%) 합금을 이용하여 석출물과 냉간가공 시 발생하는 전위가 형상기억특성 및 변태온도에 미치는 어닐링 온도의 영향에 대해서 체계적으 로 조사하였다.

\section{2. 실험방법}

Ti-44.5Ni-5Cu(at\%)합금과 Ti-45.2Ni-5Cu(at\%) 합금은 고주파 진공유도에서 용해하여, 용해된 잉곳을 냉간 인발 하여 $1 \mathrm{~mm}$ 의 와이어로 만들었다. 최종적으로 제작 된 와 이어의 냉간 가공률은 $20 \%$ 이다. 시차주사열분석용 시편과 인장시험용 시편을 각각 $4 \mathrm{~mm}$ 와 $60 \mathrm{~mm}$ 의 길이로 절단 한 후 표면의 산화 피막을 제거하였다. 각 시료를 Argon 분위기에서 $300{ }^{\circ} \mathrm{C} \sim 900{ }^{\circ} \mathrm{C}$ 의 온도로 $60 \mathrm{~min}$ 동안 어닐링 처리를 하였으며, 어닐링 된 시료의 산화막을 제거하기 위 하여 다시 sand paper로 가볍게 그라인딩 한 후 표면의 잔류응력을 제거하기 위하여 전해연마를 하였다. 변태온도 거동은 시차주사열량계를 사용하여 $\mathrm{N}_{2}$ 분위기에서 $10{ }^{\circ} \mathrm{C} /$ $\min$ 의 속도로 냉각 및 가열하여 측정하였다. 또한 형상기 억특성은 냉각/가열이 가능한 인장시험기를 이용하여 정하 중 열싸이클 테스트를 수행하였으며, 정하중 열싸이클 테 스트 시 $5^{\circ} \mathrm{C} / \mathrm{min}$ 의 속도로 냉각과 가열을 하였다.

\section{3. 실험결과}

그림 1 은 각 온도에서 어닐링 처리한 Ti-rich 조성인 Ti-44.5Ni-5Cu 합금의 변태 거동을 조사하기 위하여 DSC 측정을 하여 얻어진 곡선을 나타내었다. (a)와 (b)는 냉각 및 가열시 측정한 곡선들이다. 그림 1 (a)와 (b)에서와 같 이 $300{ }^{\circ} \mathrm{C}$ 어닐링재의 경우 변태 열량은 각각 $0.07 \mathrm{~W} / \mathrm{g}$, $0.11 \mathrm{~W} / \mathrm{g}$ 의 값을 나타냈으며, 어닐링 처리 온도가 증가할 수록 열량은 증가하며 $500{ }^{\circ} \mathrm{C}$ 이상의 온도에서는 일정하게

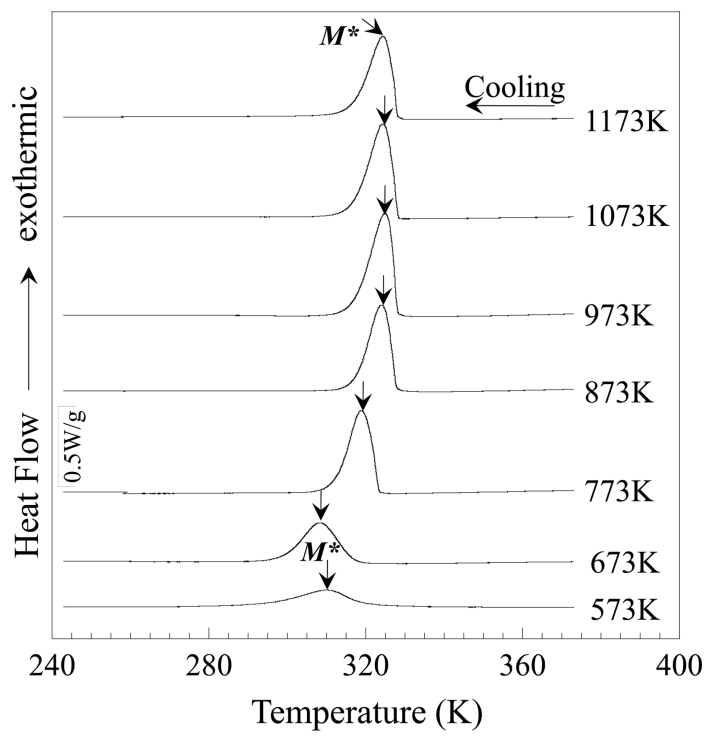

(a)

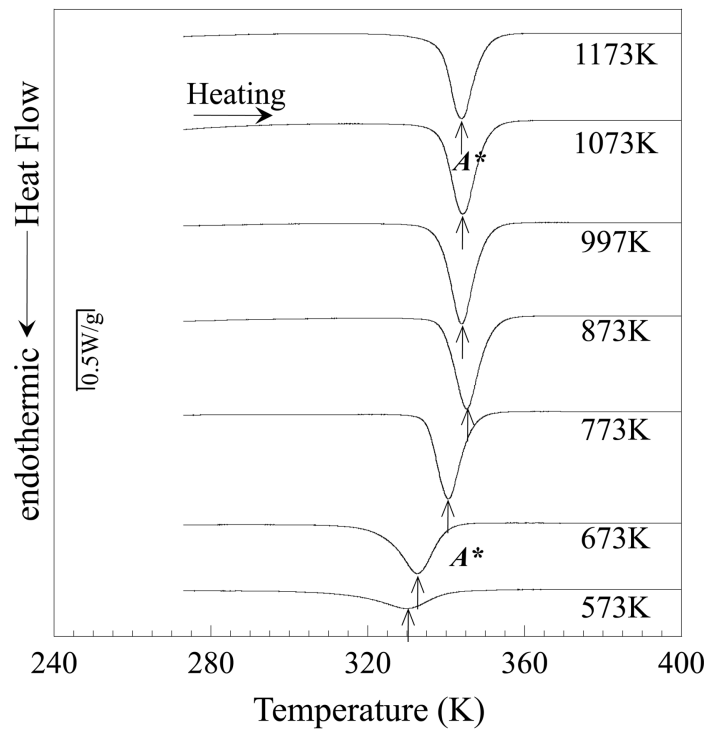

(b)

Fig. 1. Transformation behavior of Ti-44.5Ni-5Cu(at\%) after annealing at various temperature: (a) forward transformations on cooling; (b) reverse transformations on heating. 
유지되었다. 변태 구간은 $300^{\circ} \mathrm{C}$ 에서 냉각 및 가열시 각각 $30.1 \mathrm{~K}, 22.0 \mathrm{~K}$ 를 나타냈으며, 어닐링 온도가 증가함에 따라 감소하여 어닐링 온도 $500{ }^{\circ} \mathrm{C}$ 에서는 각각 $10.5 \mathrm{~K}, 11.6 \mathrm{~K}$ 이 며 그 이상의 온도에서는 거의 일정하게 유지되었다.

그림 2은 각 온도에서 어닐링 처리한 Ni-rich 조성인 Ti-45.2Ni- $5 \mathrm{Cu}$ 합금의 변태 거동을 조사하기 위하여 DSC 측정을 하여 얻어진 곡선을 나타내었다. (a)와 (b)는 가열 및 냉각 시 측정한 곡선들이다. 그림에서와 같이 변태 열 량 및 변태 구간은 Ti- $44.5 \mathrm{Ni}-5 \mathrm{Cu}$ 합금과 같은 경향을 나

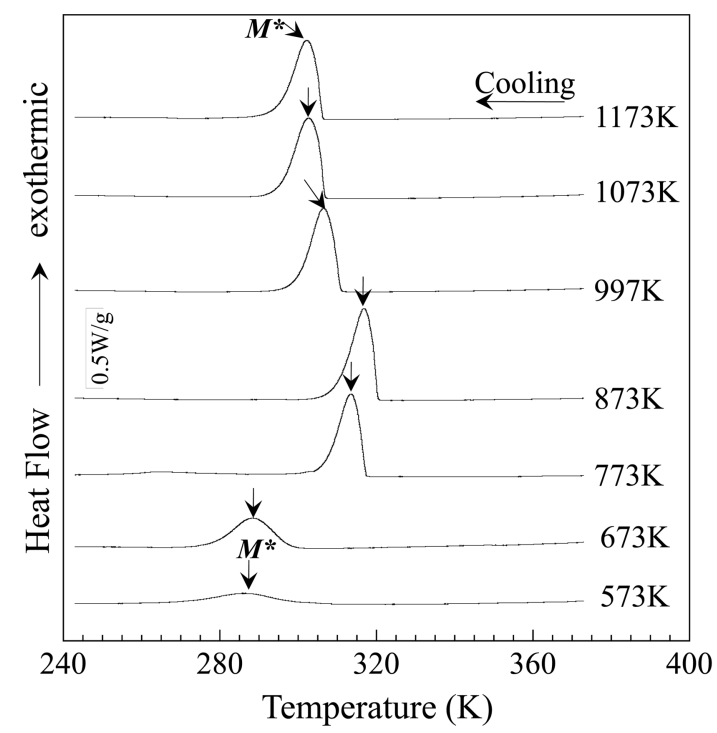

(a)

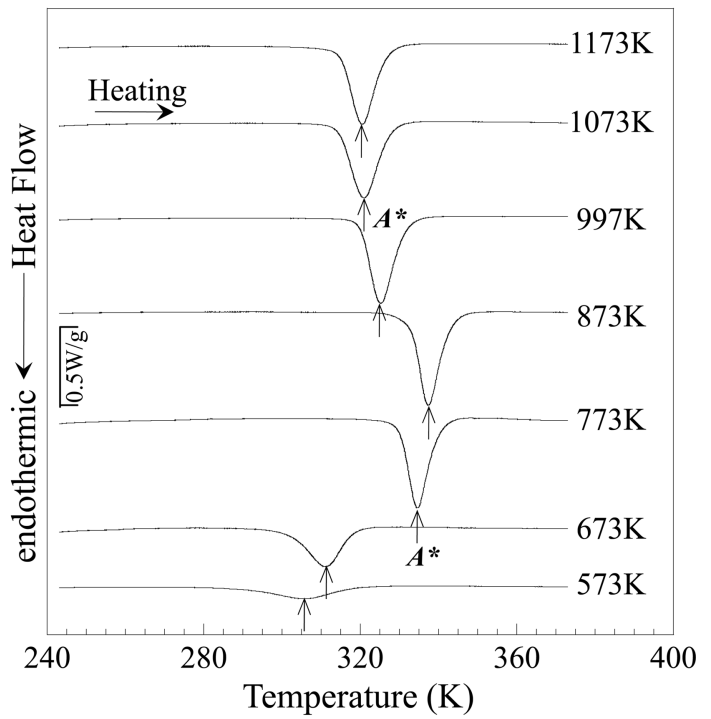

(b)

Fig. 2. Transformation behavior of $\mathrm{Ti}-45.2 \mathrm{Ni}-5 \mathrm{Cu}(\mathrm{at} \%)$ after annealing at various temperature: (a) forward transformations on cooling; (b) reverse transformations on heating.
타내었다.

이러한 변태 열량과 변태 인터벌의 변화는 마르텐사이트 변태 분률과 어닐링처리 후 잔류하고 있는 전위의 량에 의 해서 결정이 된다. 마르텐사이트 변태분률은 냉간가공에 의 해 도입된 전위의 량이 감소함에 따라 증가를 하며, 이러 한 전위의 량은 어닐링 온도가 증가함에 따라 감소한다. 또한 이러한 전위는 마르텐사이트 변태의 진행을 막는 pinning point로써, 전위의 량이 많을수록 변태 구간은 커 진다. 어닐링온도가 증가하여 회복 및 재결정에 의해 함에 따라 전위가 감소함에 따라 변태 구간은 감소하게 된다. 한편 $300{ }^{\circ} \mathrm{C}$ 에서 어닐링 된 $\mathrm{Ti}-45.2 \mathrm{Ni}-5 \mathrm{Cu}$ 합금의 변태 구간이 Ti-44.5Ni-5Cu 합금보다 약 $8 \mathrm{~K}$ 높다. Ti- $45.2 \mathrm{Ni}-$ $5 \mathrm{Cu}$ 합금은 냉간가공에 의해 도입된 전위 외에도 변태 구 간을 증가시키는 다른 요인인 미세한 Ni-rich 석출물이 생 성되었다고 예상되어진다.

그림 3은 그림 1 및 그림 2에서 얻어진 $\mathrm{B} 2 \rightarrow \mathrm{B} 19$ ' 변태 피크 온도 $M^{*}$ 의 어닐링처리 온도 의존성을 나타내었다. 그림에서와 같이 Ti-rich 조성인 Ti- $44.5 \mathrm{Ni}-5 \mathrm{Cu}$ 합금은 어닐 링 온도가 증가함에 따라 단순 증가하여 $873 \mathrm{~K}$ 이상의 온 도에서는 일정을 값을 나타내고 있다. 반면 Ni-rich 조성인 Ti-45.2Ni-5Cu 합금은 어닐링 온도 증가와 함께 변태온도 는 증가하다가 $887 \mathrm{~K}$ 에서 최대값을 보인 후 어닐링 온도 증가와 함께 감소하여 $1073 \mathrm{~K}$ 이상의 온도에서는 일정을 값을 보이고 있다. 이와 같은 변태온도의 어닐링 온도 의 존성을 설명하기 위하여 그림에서와 같이 3 가지 영역으로

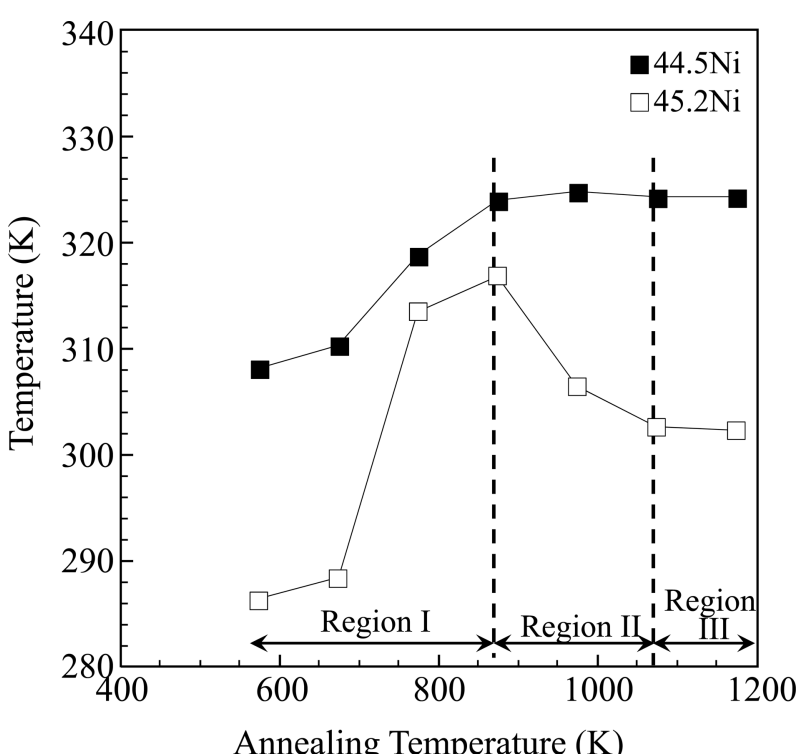

Fig. 3. Effect of annealing temperature on martensitic transformatior temperatures for $\mathrm{Ti}-44.5 \mathrm{Ni}-5 \mathrm{Cu}(\mathrm{at} \%)$ and $\mathrm{Ti}-45.2 \mathrm{Ni}-5 \mathrm{Cu}(\mathrm{at} \%$ alloys. 
나누었다. 이 3 가지 영역은 $\mathrm{Ti}-45.2 \mathrm{Ni}-5 \mathrm{Cu}$ 합금을 기준으로 변태온도가 증가하는 $573 \mathrm{~K} \sim 873 \mathrm{~K}$ 구간을 Region I, 변 태온도가 감소하는 $873 \mathrm{~K} \sim 1073 \mathrm{~K}$ 구간을 Region II, 그 리고 변태온도 변화가 없는 $1073 \mathrm{~K} \sim 1173 \mathrm{~K}$ 구간을 Region III으로 정의하였다. 일반적으로, 변태온도에 영향 을 미치는 인자는 매트릭스 내 $\mathrm{Ni}$ 조성, 석출물의 분포 상태(밀도 및 사이즈), 냉간가공 시 발생하는 전위가 있다 고 알려져 있다 $[19,20]$. 매트릭스 내 $\mathrm{Ni}$ 조성이 증가할수 록 변태온도는 감소하며 Ni-rich 석출은 미세하고 치밀할 수록 변태온도를 저하시키며 조대화 될수록 변태온도에 미 치는 영향이 감소한다고 알려져 있다. 냉간가공 시 도입된 전위는 변태온도를 감소시킨다고 알려져 있다.

그림 4 에는 과거에 보고된 $\mathrm{Ti}_{X}-\mathrm{Ni}_{(92-X)}-8 \mathrm{Cu}(\mathrm{at} \%)$ 합금의 부분 상태도를 나타내었다 [21]. 그림에서와 같이 $(\mathrm{Ni}+\mathrm{Cu})$ 조성이 $49.6 \mathrm{at} \%$ 이하일 때는 $\mathrm{B} 2$ 상과 $\mathrm{Ti}$-rich $\mathrm{Ti}_{2}\left(\mathrm{Ni}_{1-}\right.$ $\mathrm{YCu}_{\mathrm{Y}}$ ) 석출물이 공존하고 있고 고용도는 온도에 대한 의 존성을 보이지 않는다. $\mathrm{Ti}-\mathrm{Ni}$ 이원계 상태도에서는 $\mathrm{Ti}_{2} \mathrm{Ni}$ 석출물은 응고 시 공정반응에 의해서 생성이 되며 열처리 온도에 의존하지 않고 안정상으로 존재하게 된다. 이는 그 림에서와 같이 $\mathrm{Ti}_{X}-\mathrm{Ni}_{(92-X)}-8 \mathrm{Cu}(\mathrm{at} \%)$ 합금의 부분 상태도와 거의 유사하며 열처리 온도 변화에 따른 석출 거동의 변화 가 없다는 것을 의미한다. 본 연구에서의 $\mathrm{Ti}-44.5 \mathrm{Ni}-5 \mathrm{Cu}$ 합 금이 이 구역에 해당된다고 사료된다. 그림 3에서와 같이 어닐링 온도의 증가에 따라 $\mathrm{Ti}-44.5 \mathrm{Ni}-5 \mathrm{Cu}$ 합금의 변태온도 는 단순 증가하다가 포화가 된다. 이는 석출물의 거동과는 무관하게 어닐링 온도 증가함에 따라 회복 및 재결정에 의

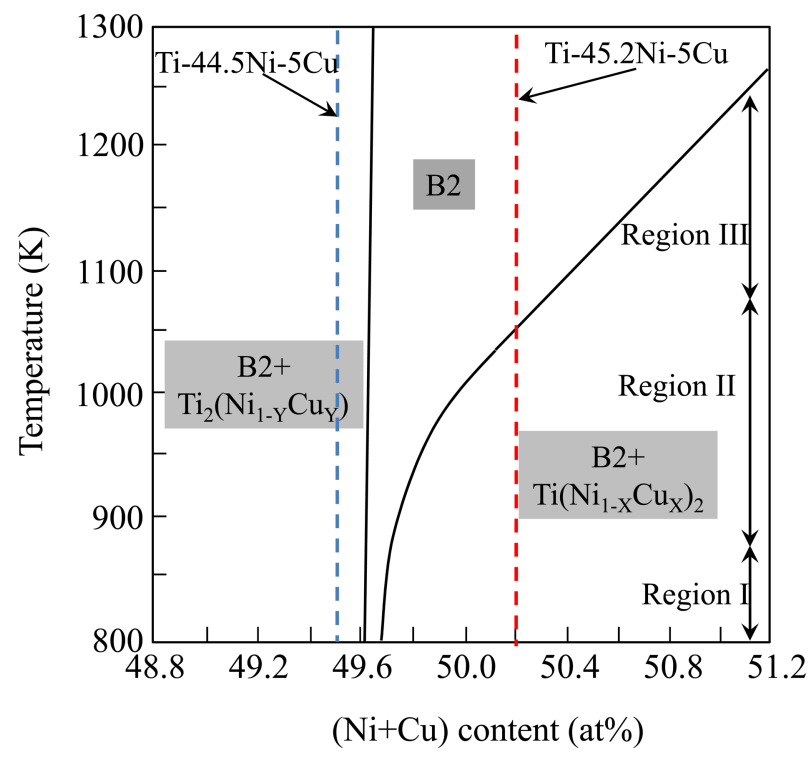

Fig. 4. Partial phase diagram of Ti-Ni-8Cu(at\%) system
해 냉간 가공 시 도입된 전위가 감소하게 된다. 그러므로 어닐링 온도의 증가함에 따라 변태온도가 증가하게 되고 $873 \mathrm{~K}$ 이상의 온도에서 재결정이 완료되어 변태온도가 포 화되는 것으로 사료된다.

한편 Ni-rich 조성인 Ti-45.2Ni-5Cu합금은 고온에서는 $\mathrm{B} 2$ 단상 영역에 있지만 저온에서는 $\mathrm{B} 2$ 상과 $(\mathrm{Ni}+\mathrm{Cu})$-rich $\mathrm{Ti}\left(\mathrm{Ni}_{1-\mathrm{x}} \mathrm{Cu}_{\mathrm{x}}\right)_{2}$ 석출물과 공존 영역에 위치한다. 그림에서와 같이 $(\mathrm{Ni}+\mathrm{Cu})-r i c h$ 조성 영역에서는 온도가 증가할수록 매 트릭스의 $\mathrm{Ni}$ 고용도는 증가하는 것을 알 수 있다. 그림 3 에서 $\mathrm{Ti}-45.2 \mathrm{Ni}-5 \mathrm{Cu}$ 합금의 변태온도가 증가하는 Region $\mathrm{I}(<873 \mathrm{~K})$ 에서는 그림 4 에서 보는 바와 같이 매트릭스의 $\mathrm{Ni}$ 고용도의 온도의존성은 거의 없음을 알 수 있고, Nirich $\mathrm{Ti}\left(\mathrm{Ni}_{1-\mathrm{x}} \mathrm{Cu}_{\mathrm{x}}\right)_{2}$ 석출물은 미세하게 생성되어 있을 것이라 고 예측이 되며 냉간가공에 의해서 도입된 전위는 어닐링 후에도 잔류하고 있을 것이라고 예상이 된다. $(\mathrm{Ni}+\mathrm{Cu})-\mathrm{rich}$ 석출물의 생성으로 매트릭스의 $\mathrm{Ni}$ 농도는 감소하여 변태온 도는 상승할 것이고 어닐링 온도의 증가는 일부 전위를 회 복시켜 전위 밀도를 감소시키므로 변태온도는 상승할 것이 라고 사료된다. 이와 같은 이유로 Region I에서는 어닐링 온도가 증가함에 따른 변태온도는 증가하게 된다. 변태온 도가 감소하는 Region $\mathrm{II}(873 \mathrm{~K}$ 이상 $)$ 에서는 재결정이 완 료되어 어닐링 온도 변화에 따른 전위 밀도의 변화는 없을 것이라고 사료된다. 그림 4에서와 같이 온도가 증가함에 따른 매트릭스의 $\mathrm{Ni}$ 고용도는 증가하고 있다. 그러므로 어 닐링 온도가 증가함에 따라 매트릭스의 $\mathrm{Ni}$ 농도는 증가하 게 되어 변태온도는 감소하는 것으로 사료된다. 변태온도 가 포화되는 Region III에서는 전위 및 석출물이 없는 $\mathrm{B} 2$ 단상 영역이므로 그림 3에서와 같이 변태온도의 어닐링온 도 의존성은 보이지 않는다.

각 합금의 어닐링 열처리 온도가 형상기억특성에 미치는 영향을 조사하기 위해서 정하중 열싸이클 테스트를 수행하 였다. 그림 5 에서는 $\mathrm{Ti}-45.2 \mathrm{Ni}-5 \mathrm{Cu}$ 합금의 $773 \mathrm{~K}-60 \mathrm{~min}$ 어닐링 시편의 정하중 열싸이클 테스트 결과 얻어진 Strain-Temperature Curve를 나타내었다. 시편을 모상 이상 의 온도까지 가열하여 일정하중을 부하한 뒤 마르테사이트 변태 종료 온도 $\left(M_{f}\right)$ 이하까지 냉각한 후 다시 마르텐사이 트 역변태 종료온도 $\left(A_{f}\right)$ 이상까지 가열하여 테스트을 반복 적으로 수행하였다. 부하 하중은 $50 \mathrm{MPa}$ 부터 시작하여 50 $\mathrm{MPa}$ 씩 증가시켜가며 진행하였다. 그림 5에서와 같이 Strain-Temperature 커브는 각 하중별로 쉽게 구별하기 위 하여 세로축으로 약간씩 이동시켰다. 각 변태온도의 정의 와 각 종 Strain은 $350 \mathrm{MPa}$ 응력 하에 얻어진 커브에서 표시하였다. Strain $e_{M}$ 은 냉각 시 발생되는 총 변태 변형 


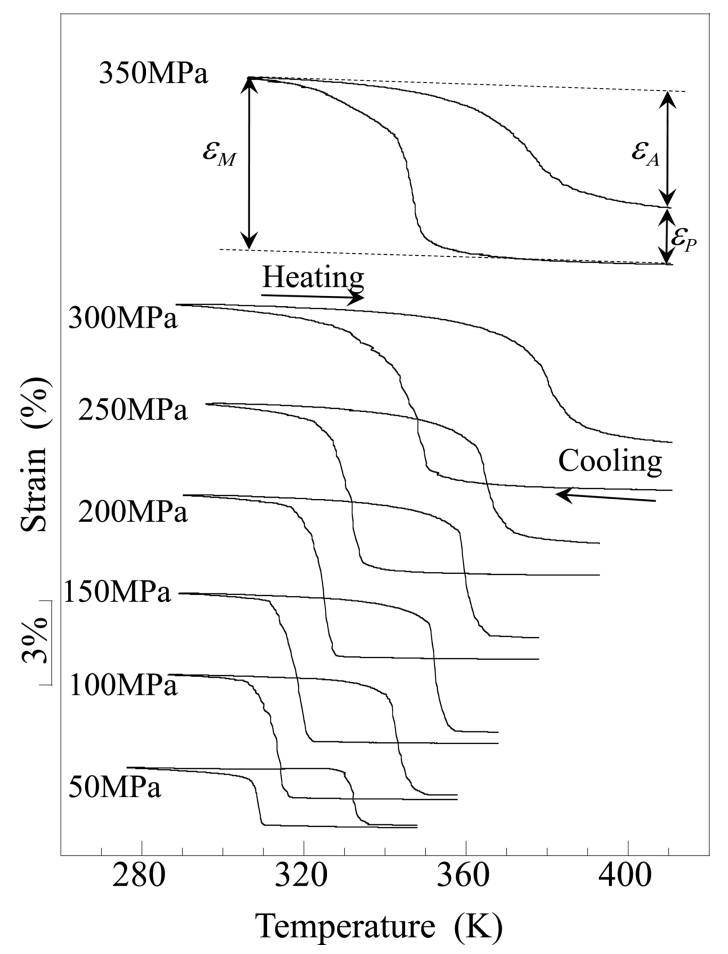

Fig. 5. Strain-temperature curves under constant stresses in the Ti $45.2 \mathrm{Ni}-5 \mathrm{Cu}(\mathrm{at} \%)$ annealed at $773 \mathrm{~K}$ for $60 \mathrm{~min}$.

량이며, $e_{\mathrm{A}}$ 은 가열 시 $\mathrm{B} 19^{\prime} \rightarrow \mathrm{B} 2$ 로의 역변태에 의한 회복 한 변형량이다. $e_{P}$ 는 역변태 시 회복되지 않은 소성변형률 이다. 실선과 점선은 각각 냉각과 가열을 나타낸다. $e_{M}$ 은 응력이 증가함에 따라 증가를 한 후 $350 \mathrm{MPa}$ 에서 $5.5 \%$ 의 값을 나타내었다. $e_{P}$ 은 $100 \mathrm{MPa}$ 에서 도입되어지기 시작하 면서 응력이 증가함에 따라 증가하였다.

그림 6 은 $\mathrm{Ti}-45.2 \mathrm{Ni}-5 \mathrm{Cu}$ 조성에서 $773 \mathrm{~K}-60 \mathrm{~min}$ 로 어닐링 시편에서 측정된 $e_{P}$ 와 $e_{A}$ 의 부하하중 의존성을 보 여준다. $e_{A}$ 는 부하하중이 증가함에 따라 증가하여 200 $\mathrm{MPa}$ 에서 $5.2 \%$ 로 최대값을 보인 후 서서히 감소하였다. 반 면에, $e_{P}$ 는 $100 \mathrm{MPa}$ 에서 도입되기 시작한 후 응력이 증가 함에 직선적으로 증가하여, 최대부하하중에서 $1.9 \%$ 의 값을 나타내었다. 형상기억거동의 안정성은 일반적으로 슬립임 계응력 $\left(\sigma_{s}\right)$ 와 최대회복변형률 $\left(\varepsilon_{A}^{m a x}\right)$ 으로 알 수 있다. 점선 화살표가 나타내는 최대회복변형률은 회복변형률 $\left(e_{A}\right)$ 이 최 대인 값을 의미한다. 또한 실선화살표가 나타내는 슬립임 계응력은 각 부하하중에서 구한 소성변형률을 외삽한 후 소성변형률이 $0.5 \%$ 지점에서의 응력을 의미한다. 여기서 소성변형률 $0.5 \%$ 는 인장시험기의 오차범위를 나타낸다. 즉, 그림 6에서 보는 바와 같이 $773 \mathrm{~K}-60 \mathrm{~min}$ 의 어닐링 시 편에서 최대회복변형률과 슬립임계응력은 각각 대략 $5.2 \%$

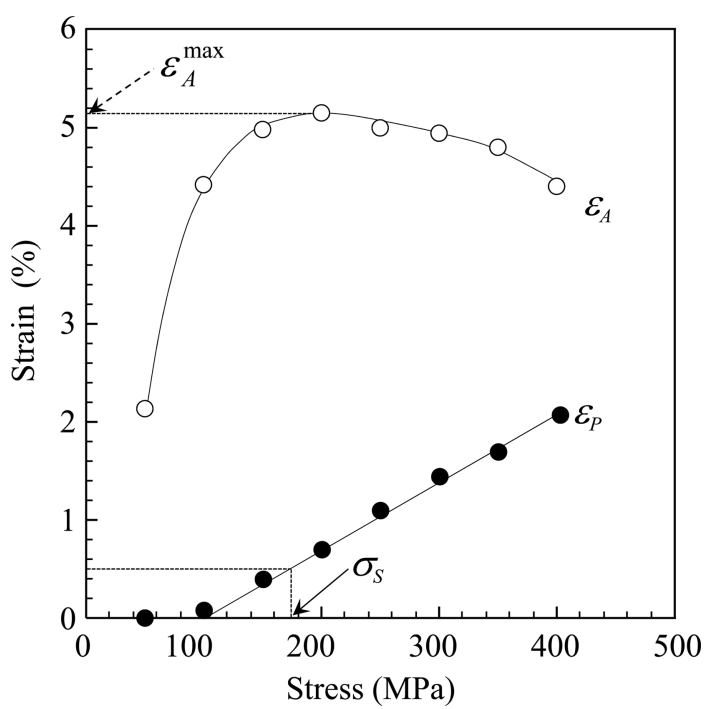

Fig. 6. Stress dependence of recovery and plastic strains $\left(e_{A}\right.$ and $\left.e_{P}\right)$ in the $\mathrm{Ti}-45.2 \mathrm{Ni}-5 \mathrm{Cu}(\mathrm{at} \%)$ annealed at $773 \mathrm{~K}$ for $60 \mathrm{~min}$

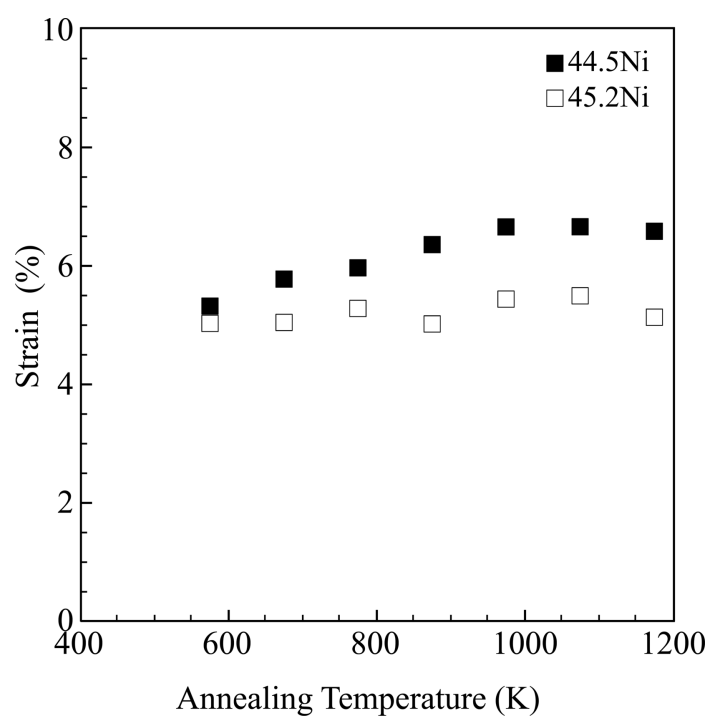

Fig. 7. Effect of annealing temperature on maximum recovery strain in the $\mathrm{Ti}-44.5 \mathrm{Ni}-5 \mathrm{Cu}($ at $\%)$ and $\mathrm{Ti}-45.2 \mathrm{Ni}-5 \mathrm{Cu}($ at $\%)$ alloys.

와 $143 \mathrm{MPa}$ 이다.

그림 7 은 Ti- $45.2 \mathrm{Ni}-5 \mathrm{Cu}$ 합금과 $\mathrm{Ti}-44.5 \mathrm{Ni}-5 \mathrm{Cu}$ 합금의 최대회복변형률을 어닐링 온도에 대하여 나타낸 그래프이 다. Ti-45.2Ni-5Cu 합금에서 최대회복변형률에 대한 어닐 링 온도 의존성은 거의 나타나지 않았다. 반면에 Ti$44.5 \mathrm{Ni}-5 \mathrm{Cu}$ 합금에서 최대회복변형률은 어닐링 온도가 증 가함에 따라 서서히 증가한 후 $973 \mathrm{~K}$ 이상에서는 거의 일 정하게 유지되었다.

그림 8 은 Ti- $45.2 \mathrm{Ni}-5 \mathrm{Cu}$ 합금과 $\mathrm{Ti}-44.5 \mathrm{Ni}-5 \mathrm{Cu}$ 합금의 슬립임계응력을 어닐링 온도에 대하여 나타낸 그래프이다. 


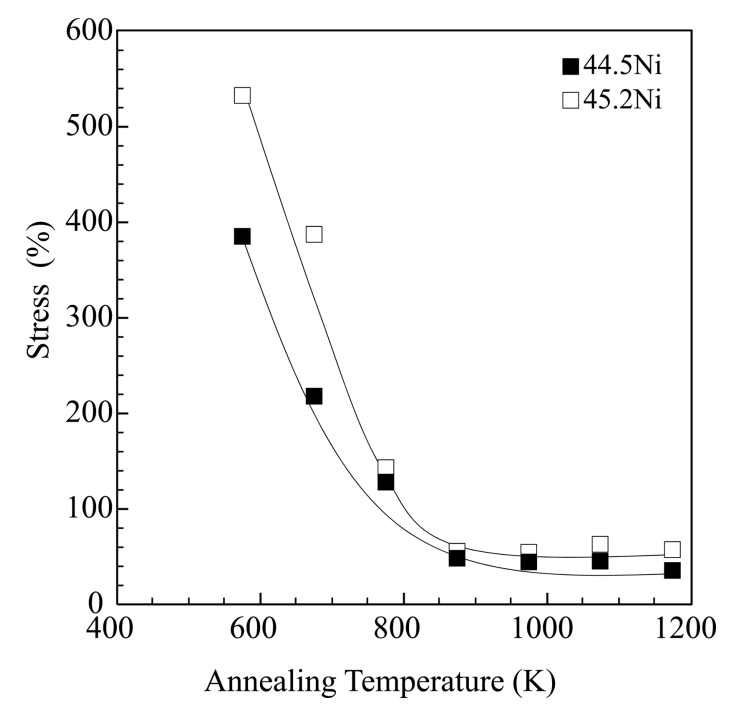

Fig. 8. Effect of annealing temperature on critical stress for slip in the $\mathrm{Ti}-44.5 \mathrm{Ni}-5 \mathrm{Cu}(\mathrm{at} \%)$ and $\mathrm{Ti}-45.2 \mathrm{Ni}-5 \mathrm{Cu}($ at $\%)$ alloys.

두 조성 모두 어닐링 온도가 증가함에 따라 급격히 감소하 여 $873 \mathrm{~K}$ 에서 각각 $50.7 \mathrm{MPa}, 56.3 \mathrm{MPa}$ 의 값을 보인 후 거의 일정하게 유지되었다. 또한, $873 \mathrm{~K}$ 이하의 어닐링 온 도에서 Ti- $45.2 \mathrm{Ni}-5 \mathrm{Cu}$ 합금의 슬립임계응력이 Ti-44.5Ni$5 \mathrm{Cu}$ 합금의 슬립임계응력보다 상대적으로 높은 값을 나타 냈으며, $873 \mathrm{~K}$ 이상에서는 두 조성 모두 대략 $50 \mathrm{MPa}$ 로 일정하게 유지되었다. 첫 번째 시료인 Ti-45.2Ni-5Cu 합금 에서 석출되는 $\mathrm{Ti}\left(\mathrm{Ni}_{1-\mathrm{x}} \mathrm{Cu}_{\mathrm{x}}\right)_{2}$ 은 그림 4 에서 보는 바와 같이 $573 \mathrm{~K}$ 에서 석출된 미세한 $\mathrm{Ti}\left(\mathrm{Ni}_{1-\mathrm{x}} \mathrm{Cu}_{\mathrm{x}}\right)_{2}$ 이 어닐링 온도가 증가함에 따라 점점 조대해진 후 $873 \mathrm{~K}$ 이상에서는 어닐 링 온도가 증가함에 따라 석출물이 Matrix로 다시 재고용 되어진다. 반면에 두 번째 시료인 Ti- $44.5 \mathrm{Ni}-5 \mathrm{Cu}$ 합금에서 석출되는 $\mathrm{Ti}_{2}\left(\mathrm{Ni}_{1-\mathrm{y}} \mathrm{Cu}_{\mathrm{y}}\right)$ 은 어닐링 온도가 증가하여도 크기 및 밀도의 변함이 없고 재고용 되지 않는 안정된 초정석출 물이다. 이러한 초정석출물은 슬립임계응력 변화에 영향을 미치지 않으므로 Ti-44.5Ni-5Cu의 어닐링 온도에 대한 슬 립임계응력의 변화는 오직 전위의 영향만 받는다. 한편 두 조성 모두 냉간가공 후 생성 된 전위 (가공전위)는 어닐링 온도가 증가함에 따라 감소하여 $873 \mathrm{~K}$ 이상에서는 전위의 회복이 완료된다. 이러한 결과로 어닐링 온도 $873 \mathrm{~K}$ 이하 에서는 상대적으로 미세한 석출물이 생성된 Ti-45.2Ni-5Cu 합금의 슬립임계응력이 더 높은 값을 나타냈으며, 전위가 모두 회복되고 $\mathrm{Ti}\left(\mathrm{Ni}_{1-\mathrm{x}} \mathrm{Cu}_{\mathrm{x}}\right)_{2}$ 석출물이 재고용되는 $873 \mathrm{~K}$ 이상에서는 두 합금 모두 전위 및 석출물의 영향을 받지 않기 때문에 슬립임계응력이 일정하게 유지된다.

\section{4. 결 론}

본 연구에서는 Ti-rich Ti- $44.5 \mathrm{Ni}-5 \mathrm{Cu}(\mathrm{at} \%)$ 와 $(\mathrm{Ni}, \mathrm{Cu})-$ rich Ti-45.2Ni-5Cu(at\%) 합금을 이용하여 석출물과 냉간가 공 시 발생하는 전위가 형상기억특성 및 변태온도에 미치 는 어닐링 온도의 영향에 대해서 체계적으로 조사하여 다 음과 같은 결론을 얻었다.

Ti-rich Ti-44.5Ni-5Cu(at\%)합금은 어닐링 온도가 증가함 에 따라 변태온도는 증가하고 $873 \mathrm{~K}$ 이상에서는 일정하게 유지되었다. 이 합금은 석출물의 거동과는 무관하여 냉간 가공에 의해서 도입된 전위가 어닐링 온도의 증가와 함께 감소하여 변태온도가 증가하고 재결정이 완료된 $873 \mathrm{~K}$ 이 상에서는 일정하였다

$(\mathrm{Ni}, \mathrm{Cu})$-rich Ti-45.2Ni-5Cu(at\%) 합금은 저온에서 $\mathrm{Ti}\left(\mathrm{Ni}_{1-\mathrm{x}} \mathrm{Cu}_{\mathrm{x}}\right)_{2}$ 석출물의 생성으로 매트릭스 내의 $\mathrm{Ni}$ 농도가 감소하여 변태온도는 증가하였고 $873 \mathrm{~K}$ 이상에서는 석출 물이 매트릭스 내에 재고용되어 변태온도는 감소하였고 $1073 \mathrm{~K}$ 이상에서는 일정하게 유지되었다.

정하중 열싸이클 테스트 결과 $773 \mathrm{~K}$ 이하의 어닐링 재 에서는 $(\mathrm{Ni}, \mathrm{Cu})$-rich Ti-45.2Ni-5Cu(at\%) 합금의 슬립임 계응력이 더 높게 나타났으며 이는 미세한 $\mathrm{Ti}\left(\mathrm{Ni}_{1-\mathrm{x}} \mathrm{Cu}_{\mathrm{x}}\right)_{2}$ 석출물의 영향으로 사료되며 $873 \mathrm{~K}$ 이상의 온도에서는 두 합금은 유사한 형상기억특성을 나타내었다.

\section{감사의 글}

이 논문은 동아대학교 연구년의 결과물임

\section{REFERENCES}

1. S. Miyazaki, Y, Ohmi, K. Otsuka, and Y. Suzuki, J. de Phys. 43, C4-255 (1982).

2. S. Miyazaki, In: T.W. Duerig et al, editors. Engineering Aspects of Shape Memory Alloys, Butterworth-Heinemann 394 (1990).

3. S. Miyazaki and K. Otsuka, Metall. Trans. A 17A, 53 (1986).

4. D. Wurzel, Mater. Sci. Eng. A 273-275, 634 (1999).

5. S. Miyazaki and K. Otsuka, Metall. Trans. A 17A, 5 (1986).

6. Miyazaki, I. Shiota, K. Otsuka, and H. Tamura. MRS Int'l. Mtg. on Adv. Mats. 9, 153 (1989).

7. J. I Kim and S. Miyazaki, Acta. Mater. 53, 4545 (2005).

8. T. H. Nam, T. Saburi, and K. Shimizu, Mater. Trans. JIM 31, 959 (1990). 
9. C. M. Hwang, M. Meichle, M. B. Salamon, and C. M. Wayman, Phil. Mag A 47, 9 (1983).

10. C. M. Hwang and C. M. Wayman, Scripta Metall. 17, 1449 (1983).

11. J. I. Kim, Y. Liu, and S. Miyazaki, Acta Mater. 52, 487 (2004).

12. T.-H. Nam and G.-C. Hur, J. Korean Inst. Met. \& Mater. 32, 503 (1994).

13. T. H. Nam, T. Saburi, and K. Shimizu, Mater. Trans. JIM 31, 814 (1991).

14. T. H. Nam, T. Saburi, and K. Shimizu, Mater. Trans. JIM 31, 959 (1990).

15. T. H. Nam, T. Saburi, and K. Shimizu, Mater. Trans. JIM
33, 814 (1990).

16. T. H. Nam, T. Saburi, Y. Nakata, and K. Shimizu, Mater. Trans. JIM 31, 1050 (1990).

17. T. Saburi, K. Komatsu, S. Nenno, and Y. Watanabe, J. LessCommon Met. 217, 118 (1986).

18. T. Tadaki and C. M. Wayman, Metallography 15, 233 (1982).

19. K. H. Eckelmeyer, Scripta Metall. 10, 667 (1976).

20. S. Miyazaki, Y. Igo, and K. Otska, Acta Metall. 34, 2045 (1986).

21. S. M. Tan, S. Miyazaki, T. Ueki, and H. Horikawa, Mater. Sci. Eng. A 30, 132 (1997). 